\title{
VALOR DO INTERROGATÓRIO NO RASTREAMENTO DE INFECÇÃO CHAGÁSICA
}

\section{Maurício Gomes Pereira}

Esse trabalho apresenta análise sobre a associação entre interrogatório de picada do barbeiro e resultados da reação de fixação de complemento. O propósito foi estimar, nas condições usuais de funcionamento de um serviço de saúde, o valor diagnóstico do interrogatório sobre picada do barbeiro em infeção chagásica. Só foram incluídos aqueles individuos cujos exames laboratoriais estavam confirmados, positivos ou negativos. Foram retirados da análise 259 pessoas com reaçōes divergentes. $\mathrm{Na}$ anamnese, ao mesmo tempo que a pergunta sobre antecedentes de picada de inseto era feita, eram mostrados 5 insetos adultos. Os resultados foram os seguintes em 2.154 pessoas: prevalência da infecção pelo exame laboratorial (14,5\%) e de história positiva de contato com o barbeiro (11,5\%). A coincidência de exame e história positivos ocorreu em $2,5 \%$ e de ambos negativos em $76,5 \%$, perfazendo um total de concordância de $79 \%$ (eficiência do interrogatório). A sensibilidade do interrogatório foi baixa $(17,3 \%$ ) e a especificidade alta (89,5\%). O valor preditivo de uma história positiva de picada de barbeiro foi de apenas $21,5 \%$ e a de história negativa, $86,5 \%$. Esses dados apontam para a pouca utilidade de interrogatórios em rastreamento de infecçâo chagásica, e poderiam mesmo não serem realizados em bancos de sangue, ao menos que esforços sejam feitos para que a sua precisão seja aumentada.

Palavras chaves: Doença de Chagas. Rastreamento. Avaliação epidemiológica.

É prática comum em serviços de saúde, especialmente em vastas regiões onde a doença de Chagas è endèmica; perguntar-se ao paciente se ele teve contato anterior com algum triatomídeo transmissor da doença. Seria uma maneira simples de separar infectados de não-infectados, ou, pelo menos, identificar pessoas com maior chance de estarem infectadas.

Será que a anamnese conduzida nas condições usuais de funcionamento de um serviço de saúde separaria convenientemente infectados de não-infectados? Oportunidade para testar essa questão e aprofundar a análise dos dados nos foi proporcionada pelos resultados de um rastreamento realizado num banco de sangue do Distrito Federal ${ }^{3}$. Esse trabalho mostra a prevalència de infecção chagásica entre pessoas atendidas no banco de sangue do Hospital de Sobradinho - hospital-escola da Universidade de Brasília na época - durante 16 meses de funcionamento.

Sobradinho é uma das cidades-satélites do Distrito Federal, distando $25 \mathrm{~km}$ de Brasilia, sendo

Endereço para correspondência: Dr. Mauricio Gomes Pereira, Departamento de Medicina Geral e Comunitária, Universidade de Brasilia, 70910, Brasilia, DF, Brasil. Recebido para publicação em $21 / 5 / 84$. sua população (42.000 habitantes em 1970 e 64.000 habitantes em 1980), em grande parte, formada por migrantes de estados vizinhos onde a doença de Chagas é endèmica. $\mathrm{Na}$ cidade e em todo o Distrito Federal acredita-se que não haja transmissão da doença através do vetor.

$\mathrm{Na}$ ocasião desse inquérito, o banco de sangue atendia principalmente pessoas de nivel sócio-econòmico menos elevado, recentemente chegadas de diversas partes do pais, pois elas necessitavam apresentar exame médico para iniciar trabalho e eram atendidas gratuitamente se concordassem em doar sangue. Como conseqüência dessa seleção, a porcentagem de reações positivas denunciando infeç̧ão chagásica foi elevada (14,5\%), embora as pessoas atendidas fossem assintomáticas. Por ocasião do inquérito, foi anotada a discrepância entre resultados de interrogatório sobre antecedentes de contato com o vetor e os testes de laboratório. $O$ trabalho atual apresenta mais detalhes. Especificamente, a análise foi dirigida para estimar o quanto a anamnese é eficaz para prever o resultado laboratorial.

\section{MATERIAL E MÉTODOS}

O trabalho foi preparado a partir dos dados do artigo de Lima e colaboradores ${ }^{3}$. Em resumo, a 
Pereira MG. Valor do interrogatório no rastreamento de infecção chagásica. Revista da Sociedade Brasileira de Medicina Tropical 17: 133-136, Jul-Set, 1984

anamnese era feita de rotina pelo pessoal auxiliar do banco de sangue, perguntando-se ao doador em potencial se ele já tinha sido picado pelo barbeiro, ao mesmo tempo que lhe era mostrado cinco exemplares de insetos adultos (Dra. Lise Mary A Lima: comunicação pessoal). De cada pessoa, era retirado sangue, adicionado azida sódica e conservado em geladeira por um prazo nunca superior a 48 horas, até que o exame fosse realizado. No laboratório foi utilizada a reação de fixação de complemento (RFC) qualitativa em gotas, sobre placas siliconizadas, usando-se soro controle positivo e negativo. Os reagentes e materiais foram adquiridos no Laboratório Lio Serum, de Ribeirão Preto.

Foram excluidas 259 pessoas, do total de 2.413 atendidas no periodo, pois elas apresentaram reações laboratoriais duvidosas. A análise ficou limitada às 2.154 pessoas com informações sobre interrogatórios de picada do inseto e resultados laboratoriais confirmados, seja positivos ou negativos.

\section{RESULTADOS}

Os principais achados estão resumidos nas Tabelas 1 e 2 . Das 2.154 pessoas examinadas, $14,5 \%$ foram consideradas infectadas (RFC positiva) e $11,5 \%$ alegaram terem sido picadas pelo barbeiro. No entanto, apenas em $2,5 \%$ houve coincidência de história e exame positivos. A concordância de ambos história e exame negativos ocorreu em $76,5 \%$ das pessoas examinadas. Resultados não coincidentes (falso-positivos mais falso-negativos) foram encontrados em $21 \%$. A eficiência do interrogatório para rastrear o verdadeiro estado de cada examinado foi de $79 \%$.

Tabela 1 - Resultados de interrogatório sobre picada do barbeiro e de reafão sorológica em 2.154 adultos examinados em um banco de sangue do Distrito Federal.

\begin{tabular}{|c|c|c|c|c|}
\hline \multirow{3}{*}{ Interrogatório } & \multicolumn{2}{|c|}{ Sorologia $(R F C)$} & \multicolumn{2}{|c|}{ Total } \\
\hline & Positiva & Negativa & & \\
\hline & $n^{\circ} \quad(\%)$ & $n .^{o} \quad(\%)$ & $n .^{\circ}$ & $(\%)$ \\
\hline $\begin{array}{l}\text { Positivo } \\
\text { Negativo }\end{array}$ & $\begin{array}{r}54(2,5)^{\mathrm{a}} \\
258(12,0)^{\mathrm{c}}\end{array}$ & $\begin{array}{r}194(9,0)^{b} \\
1648(76,5)^{d}\end{array}$ & $\begin{array}{r}248 \\
1906\end{array}$ & $\begin{array}{l}(11,5) \\
(88,5)\end{array}$ \\
\hline Total & $312(14,5)$ & $1842(85,5)$ & 2154 & $(100,0)$ \\
\hline
\end{tabular}

RFC $=$ Reação de fixação do complemento a, b, c, d: ver tabela 2 .
Tabela 2-Indicadores de prevalência, validade $e$ valor preditivo resultantes de informações do interrogatório sobre picada do barbeiro e da reação de fixação de complemento em 2.154 adultos examinados em um banco de sangue do Distrito Federal.

\begin{tabular}{|c|c|c|}
\hline Tipo de Indicador & Fórmula* & $\begin{array}{c}\text { Resultados } \\
\%\end{array}$ \\
\hline \multicolumn{3}{|l|}{ Prevalência } \\
\hline Infecção & $a+c / a+b+c+d$ & 14,5 \\
\hline Interrogatório positivo & $a+b / a+b+c+d$ & 11,5 \\
\hline Concordância & $a+d / a+b+c+d$ & 79,0 \\
\hline Discordância & $b+c / a+b+c+d$ & 21,0 \\
\hline \multicolumn{3}{|l|}{ Validade } \\
\hline Sensibilidade & $a / a+c$ & 17,3 \\
\hline Especificidade & $d / b+d$ & 89,5 \\
\hline \multicolumn{3}{|l|}{ Valor Preditivo } \\
\hline Interrogatório positivo & $a / a+b$ & 21,8 \\
\hline Interrogatório negativo & $d / c+d$ & 86,5 \\
\hline
\end{tabular}

* Significado das letras, ver tabela 1.

A validade de um indicador pode ser melhor estimada por dois de seus componentes 24 , sensibilidade e especificidade. Eles podem ser assim interpretados (análise da tabela no sentido vertical):

a) A sensibilidade (ou co-positividade) do interrogatório $(17,3 \%)$, indica a freqüência de pessoas que alegaram terem sido picadas pelo inseto entre aquelas com exame laboratorial positivo. Em outras palavras, entre cada grupo de 6 pessoas classificadas como portadoras de infeç̧ão chagásica, apenas uma relatou picada do barbeiro.

b) A especificidade (ou co-negatividade) do interrogatório $(89,5 \%)$ indica a frequência de pessoas não relatando passado de picadas do inseto no grupo com RFC negativa, ou seja, entre 10 pessoas com resultados laboratoriais negativos, 9 relataram também não terem sido picadas pelo barbeiro.

O valor preditivo ou diagnóstico do interrogatório sobre picada prévia do barbeiro pode ser resumido da maneira descrita abaixo (análise da tabela no sentido horizontal). Note-se que essa é a posição que se encontra o médico diante de um paciente, onde a informação dada por este deve ser interpretada pelo médico, ainda sem resultados do exame laboratorial:

a) Para o grupo com história positiva, o valor preditivo foi de $21,8 \%$, ou seja, de cada 5 pessoas com 
Pereira MG. Valor do interrogatório no rastreamento de infecçào chagásica. Revista da Sociedade Brasileira de Medicina Tropical 17: 133-136, Jul-Set, 1984

história de picada prévia de inseto, apenas uma foi encontrada com infecção chagásica.

b) Para o grupo com história negativa, o valor preditivo foi de $86,5 \%$, ou seja, aproximadamente, de cada 10 pessoas relatando não terem sido picadas pelo barbeiro, uma estava com infecção.

$\mathrm{O}$ interrogatório produziu um número elevado de falsos negativos $(n=258$ com interrogatório negativo e exame positivo). Esta seria a situação mais temivel em relação à transmissão da doença, se somente o interrogatório fosse usado como indicador. Os falsos positivos $(n=194)$, ou seja, aqueles com anamnese positiva e exame laboratorial negativo, não teriam qualquer conseqüência na transmissão da enfermidade pois, por definição, não poderiam mesmo transmitir a doença e, alèm disso, estariam tambèm descartados de serem doadores pois relataram picada prévia do inseto, se esse fosse o único adotado para identificar infectados.

\section{DISCUSSÃO}

Em geral, os estudos epidemiológicos estão dirigidos para avaliar a associação entre duas variáveis. No caso presente tratou-se de comparar um indice mais simples (interrogatório) com outro considerado mais preciso (exame laboratorial), coletados independentemente um do outro. $21 \%$.

Os resultados mostraram uma discordância de

A baixa sensibilidade $(17,3 \%)$ é a expressão numérica do fato de que a maioria das pessoas positivas ao exame laboratorial relataram que não tinham sido picadas pelo barbeiro. Diversas possibilidades podem ser levantadas para explicar os achados:

a) informação incorreta do doador, o que atestaria uma possível baixa confiabilidade dessa informação; b) a maneira de formulação da pergunta o que pode fazer variar as respostas; c) a picada é noturna e passa despercebida e d) outros métodos de transmissão não envolvendo inseto vetor podem ser os responsáveis pela infecção, tais como transfusão e via transplacentária.

A alta especificidade $(89,5 \%)$ é expressão de que a grande maioria das pessoas negativas ao exame laboratorial foi corretamente identificada. Os restantes $(10,5 \%)$, os falsos positivos, podem ser explica- dos pela possibilidade de, havendo respondido corretamente, terem tido contato com barbeiros não infectados.

Parte das inconsistências encontradas pode ser devida à imprecisão do exame laboratorial pois esse foi usado como o parâmetro de referência. Acredita-se que tanto o nível de confiabilidade (isto é, a reprodutibilidade) dos testes sorológicos, como a sua validade em corretamente identificar infectados e nãoinfectados, necessitam ainda ser melhorados ${ }^{15}$. Os dados do trabalho aqui apresentado não podem esclarecer esse aspecto. No entanto, pode-se adiantar que, nos casos em que o exame laboratorial utilizado não seja inteiramente preciso para separar os verdadeiros infectados dos não-infectados, essa imprecisão altera também o grau de associação que se pretende estudar (interrogatório e infecção chagásica).

Foi determinado o valor preditivo de um interrogatório positivo ou negativo nessa população. $\mathrm{Na}$ prática diária, esta é a informação que o pessoal dos serviços de saúde pode retirar do paciente na ausência de exame laboratorial, como acontece, por exemplo, na primeira consulta ou em salas de emergência. Pelos resultados apresentados, um interrogatório positivo não tem praticamente valor ao contrário da história negativa que estaria praticamente certa 9 vezes em cada 10 .

Ressalte-se que, em outras populações com niveis diferentes de prevalência de infecção - ou estruturas diversas com respeito a variáveis tais como idade, profissão e local de residência - os valores preditivos serão provavelmente diferentes. Do mesmo modo, é possivel que maneiras diversas de proceder ao interrogatório possam também fazer variar as respostas e, portanto, a validade dessa informação na determinação de infecção chagásica.

Embora a anamnese seja simples de ser realizada, os resultados apresentados permitem questionar, da maneira como ela é realizada, a sua utilidade para detectar doença de Chagas. $\bar{E}$ informação coletada rotineiramente mas que não pode ser utilizada para tomada de decisões.

\section{SUMMARY}

The association between responses to an inquiry about contact with triatomid bugs and the confirmation of infection by complement fixation test is examined in a group of 2.154 cases from a hospital blood bank. The laboratory examination revealed a 
Pereira MG. Valor do interrogatório no rastreamento de infecção chagásica. Revista da Sociedade Brasileira de Medicina Tropical 17: 133-136, Jul-Set, 1984

prevalence of infection of $14,5 \%$ and the inquiry a positive contact history of $11,5 \%$. However, positive findings for both methods coincided in only $2,5 \%$, while negative findings coincided in $76,5 \%$. The total concordance of findings, or the efficacy of the inquiry to correctly indicate the state of infection, was $79 \%$. The sensitivity of the screening instrument was low $(17,3 \%)$ and the specificity high $(89,5 \%)$. The predictive value of a positive history of contact was only $21,5 \%$, while that of a negative history was $86,5 \%$. These results indicate that inquiries carried out in this way are of little value in screening for Chagas' disease and should be discontinued in blood banks, unless their precision can be enhanced.

Key words: Chagas' disease. Screening. Epidemiologic evaluation.

\section{AGRADECIMENTOS}

O autor agradece à Dra. Lise Mary A. Lima pelas informações prestadas.

\section{REFERÊNCIAS BIBLIOGRÁFICAS}

1. Brener Z. Recent developments in the field of Chagas'disease. Bulletin of the World Health Organization 60: 463-73, 1982.

2. Chamberlain J. Evaluation of screening procedures. In: Hobson W (ed) The Theory and practice of public health. Oxford University Press, London, p. 647-660, 1975.

3. Lima LMA, Sacramento HS, Gama MP, Muniz JD. Inquérito sorológico para doença de Chagas em doadores de sangue da Unidade Integrada de Saúde de Sobradinho. Revista Goiana de Medicina 27: 201-215, 1981.

4. Ruiz F. Estatística básica aplicada à saúde. Centro de Documentação do Ministério de Saúde, Brasilia, pp. $72-76,1983$.

5. Teixeira ARL, Pereira LM. Discrepàncias entre resultados de très reações sorológicas empregadas para diagnóstico da doença de Chagas. Revista Brasileira de Biologia 41: 789-795, 1981. 